Creating Productive and Upcoming Sport Education Profesional Hmzanwadi University

Vol.4, No.2, Desember 2021, Hal. 140-148

e-ISSN 2614-8781

\title{
PENGARUH LATIHAN PASSING BAWAH MENGGUNAKAN MEDIA DINDING DENGAN MEMAKAI SASARAN GARIS LURUS TERHADAP KEMAMPUAN PASSING BAWAH
}

\author{
Shandy Pieter Pelamonia ${ }^{1}$, Hayati ${ }^{2}$, Moh. Wahyudi Firnanda ${ }^{3}$ \\ Email: $\underline{\text { shandypieter@unipasby.ac.id }}{ }^{1}, \underline{\text { hayati@unipasby.ac.id }}{ }^{2}, \underline{\text { wahyufirnanda98@ gmail.com }}^{3}$ \\ $\mathbf{1 , 2 , 3}$ Universitas PGRI Adi Buana Surabaya
}

\begin{abstract}
Abstrak
Pelatihan menggunakan media dinding dengan sasaran garis lurus, sebagai upaya untuk meningkatkan kemampuan passing bawah bola voli. Tujuan penelitian ini untuk mengetahui pengaruh pelatihan passing bawah menggunakan media dinding dengan memakai sasaran garis lurus dan untuk mengetahui perbedaan hasil pelatihan menggunakan media dan pelatihan secara konvensional. Metode yang digunakan dalam penelitian ini adalah metode penelitian kuantitatif, yang didesain menggunakan "two groups pre test post test design" Teknik pengumpulan data penelitian ini menggunakan tes dan pengukuran ketepatan passing bawah bola voli. Data dianalisis kombinasi uji t menggunakan SPSS versi 25. Berdasarkan analisis paired t test nilai Sig. Kelompok eksperimen 0,00<0,05, maka ada pengaruh pelatihan passing bawah menggunakan media dinding dengan memakai sasaran garis lurus. Sedangkan kelompok kontrol 0,000 $<0,05$, maka ada pengaruh pelatihan secara konvensional. Berdasarkan analisis independent sample t test nilai Sig. sebesar $0,00<0,05$, maka ada perbedaan rata-rata hasil tes dan pengukuran pada kelompok eksperimen dengan kelompok kontrol. Perbedaan tersebut terlihat pada hasil analisis deskriptif yang menunjukkan pada kelompok eksperimen dengan norma klasifikasi baik sekali $50 \%$, baik 50\%, sedang 0\%, kurang 0\%, kurang sekali 0\%. Sedangkan kelompok kontrol norma klasifikasi baik sekali $0 \%$, baik $60 \%$, sedang 40\%, dan kurang, kurang sekali adalah 0\%. Dapat disimpulkan bahwa pelatihan kelompok eksperimen pengaruhnya lebih besar dari pada kelompok kontrol.
\end{abstract}

Kata Kunci: Hasil Ketepatan Passing Bawah, Media Dinding Dengan Sasaran Garis Lurus

\begin{abstract}
The training use straight line target on the wall as media, as an effort to improve the ability to pass down a volleyball. The purpose of this study is to know the effects of low-passing training use straight line on the wall target as media and to discern the differences between using media and conventional. This study use quantitative methode with two groups pretest and post test design. The study's data using precision measurement of passing below the volleyball and analyzed with t-test combination (SPSS version 25). Based on analysis of the sig value test experiment group $0.00<.05$, there is influence training bottom using straight line target on the wall. As for the control group 0,000<.05, then there is the effects of training conventional based on independent analysis of sample $t$ specimen $t$. $t$. value test of 0.00.05, there is an average difference in test results and measurements in the experiment group with the control group. The result shows that groups with an excellent 50\%, good 50\%, medium $0 \%$, less $0 \%$, poor $0 \%$, while the control group is once excellent $0 \%$, good $60 \%$, medium $40 \%$, less $40 \%$, and poor $0 \%$. It was concluded that the training of experimental groups had a greater impact than the control group.
\end{abstract}

Keywords: Precision of Passing Bellow Volleyball, Straight Line Target On The Wall 
Creating Productive and Upcoming Sport Education Profesional Hmzanwadi University

Vol.4, No.2, Desember 2021, Hal. 140-148

e-ISSN 2614-8781

\section{A. Pendahuluan}

Permainan bola voli adalah olahraga yang dapat dimainkan anak-anak sampai orang dewasa. Permainan bola voli pada dasarnya berpegang pada dua prinsip yaitu teknis dan psikis. Prinsip teknis dimaksud pemain memvoli bola dengan bagian pinggang ke atas, melambungkan bola di udara melewati net agar dapat menjatuhkan bola di atas lapangan lawan untuk mencari kemenangan dan serta mendapatkan poin dan secara sportif. Secara psikis adalah pemain harus bermain denagn semangat senang dan kerjasama dengan tim yang baik (Suharno HP, 1981 : 1).Setiap cabang olahraga memiliki teknik tersendiri, demikian pula cabang olahraga bola voli. Menurut Bachtiar dkk ( 2004 : 2.10 ). Dalam permainan bola voli terdapat lima macam cara bersentuhan dengan bola sehingga timbul juga lima teknik dasar, yaitu : 1) teknik passing atas, 2) teknik passing bawah,3) teknik servis, 4) teknik smash atau spike, 5) teknik bendungan atau block.Passing merupakan salah satu teknik dasar dalam permainan bola voli yang penting. Passing adalah mengoper bola kepada teman sendiri dalam satu tim dengan suatu teknik tertentu, sebagai langkah awal untuk menyusun pola serangan kepada regu lawan ( M. Yunus, 1992 : 79 ). Dalam permainan bola voli passing terdiri dari dua macam, yaitu : passing bawah dan passing atas.

Perlu juga di ketahui dan dipahami oleh pemain bola voli bahwa untuk memiliki passing bawah dengan baik,pemain harus mampu melakukan latihan passing bawah dengan teknik atau cara yang benar dalam pelaksanaanya. Cara pelaksanaanya passing bawah menurut Syafruddin (2004:70) adalah: "Sikap lengan betul-betul diluruskan dan di rapatkan satu tangan menempel pada tangan yang lain sehingga ibu jari sejajar. Perkenaan bola antara bagian dari pergelangan tangan dan siku, tepatnya perkenaan bola sedikit diatas pergelangan tangan. Jalan gerakan bola di passing dengan meluruskan lengan dan ayunan kedua lengan. Titik berat tubuh berada pada kaki yang di depan kedua lengan tidak begitu aktif di gerakan. Bahu sedikit terangkat, bola seolah-olah ditekan kearah yang di inginkan. Kemudian bagian lengan diayunkan sampai datar dan tubuh berada di bawah bola, bahu harus lurus menunjuk ke bola yang diinginkan".

Teknik dasar passing bawah adalah teknik pertama kali yang di ajarkan di sekolahsekolah maupun di tempat klub bola voli puput kecamatan prambon. Karena passing bawah merupakan teknik bermain bola voli yang sangat penting untuk menjalankan permainan dalam bola voli. Kegunaan passing bawah antara lain, untuk menerima bola servis dan menerima bola semash atau serangan dari lawan,untuk pengambilan bola setelah terjadi block atau bola pantulan dari net, untuk menyelamatkan bola yang sering terpental jauh di luar lapangan permainan, atau untuk pengambilan bola yang rendah dan mendadak datangnya bola atau bola yang di passing tidak dapat melewati net sehingga permainan kurang sempurna tidak dapat di mainkan dengan baik. Dalam melatih bola voli ada beberapa yang digunakan untuk melatih passing bawah yang efektif, baik menggunakan alat media dinding dengan memakai sasaran garis lurus maupun tanpa menggunakan alat dinding. Diantaranya adalah latihan passing bawah menggunakan media dinding untuk sasaran memakai garis lurus sebagai media pembantu dalam latihan.

Passing bawah menggunakan media dinding dengan memakai sasaran garis lurus bisa membantu melatih ketepatan passing bawah seorang pemain saat menerima bola servis dan smash dari lawan agar bisa menerima bola lebih akurat dan lebih sempurnah. sikap permulaan pemain memegang bola dengan kedua tangan menghadap ke dinding sasaran, pelaksanaannya bola dilemparkan atau dipantulkan ke dinding dan pantulannya berusaha untuk di passing kedinding secara berulang- ulang agar bisa meningkatkan kemampuan passing bawah dengan ketepatan sasaran bola di atas garis sebagai alat media pembantu ketepatan passing bawah. 
Ketepatan adalah kemampuan seseorang dalam mengedalikan gerakan-gerakan bebas terhadap suatu sasaran (M.Satjoto, 1995:9). Ketepatan adalah kemampuan tubuh manusia untuk mengendalikan suatu gerakan bebas mau menuju ke suatu sasaran, sasaran yang dimaksud yaitu baik sasaran berupa jarak atau suatu objek langsung yang harus dikenal. Banyak faktor yang menyebabkan hal itu terjadi salah satunya adalah konsentrasi, fokus dan kurangnya teknik latihan passing bawah (deffense). Ketepatan passing bawah juga sangat diperlukan oleh pemain bola voli saat memberikan umpan kepeda timnya untuk melakukan penyerangan ke tim lawan. Latihan passing bawah ada juga jenis latihannya biasanya digunakan untuk melatih passing bawah dengan tepat adalah passing bawah dengan dinding dengan sasaran garis karena latihan ini juga sangat tepat untuk para pemain pemula yang ingin meningkatkan kemampuan passing bawah dalam permainan bola voli.

Passing bawah juga mengambil dalam permainan bola voli. Dari semua kalangan tim tersebut passing bawah sangatlah penting baik dalam ekstrakulikkuler sekolah maupun dalam club bola voli. Passing bawah juga merupakan teknik dasar yang diperlukan dalam sebuah permainan bola voli. Strategi setiap club berbeda beda tergantung peran seorang pelatih.Namun, tim putri sering kali hanya menekankan latihan penyerangan dan tidak sedikit juga dari mereka para atlet kurang melatih teknik dasar passing bawah, sehingga masih banyak terjadi umpan yang kurang tepat pada saat latihan permainan bola voli. passing bawah ini merupakan teknik dasar yang paling penting dalam sebuah permainan atau pertahanan saat menerima serangan dari lawan.

\section{B. Metode}

Metode penelitian yang didunakan dalam penelitian ini adalah metode eksperiment dengan two group pre-test post-test desain. Sampel penelitian adalah 20 pemain bola voli klub puput kecamatan prambon dan dibagi menjadi 2 kelompok yaitu 10 kelompok eksperimen dan 10 kelompok kontrol. Teknik sampling menggunakan simple random sampling dengan alasan populasi yang digunakan homogen. Penelitian ini dilakukan selama 4 minggu dengan frekwensi latihan 1 minggu 3 kali pertemuan terlepas dari pertemuan pengambilan data. Tahap penelitian ini dibagi menjadi beberapa tahap, diantaranya adalah pre-test, treatment dan post-test. Pre-test dilakukan untuk memiliki 2 tujuan, yang pertama untuk mengetahui data awal dan kedua untuk dasar pembuatan program latihan. Untuk mendapatkan data awal digunakan tes Wall volley after one bounce dari FIVB Level 1 Coaches Manual 2012: 48

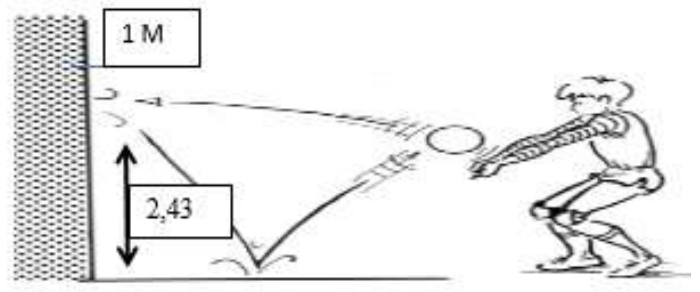

Gambar 1. Wall volley after one bounce

Treatment dilakukan dengan repetisi yang sudah ditentukan dari persentase pembebanan yang dimulai dari 30\% serta dilakukan sebanyak 4 set. Setelah kedua proses dilakukan, maka post-test dilakukan untuk mengetahui hasil dari perlakuan untuk mengetahui perbandingannya. 


\section{Hasil dan Pembahasan}

Tabel 1. Hasil Pre Test dan Post Test Kelompok Eksperimen

\begin{tabular}{ccccc}
\hline \multirow{2}{*}{ No. Sampel } & \multicolumn{2}{c}{ Hasil Tes Kemampuan Passing Bawah } & $\begin{array}{c}\text { Selisih Hasil } \\
\text { Kelompok }\end{array}$ & Klasifikasi \\
\cline { 2 - 4 } $\mathbf{1}$ & \multicolumn{2}{c}{ Kelompok Eksperimen } & B-A & \\
\cline { 2 - 4 } $\mathbf{2}$ & Pre Test (A) & Post Test (B) & 9 & B \\
$\mathbf{3}$ & 41 & 40 & 8 & BS \\
$\mathbf{4}$ & 41 & 49 & 7 & BS \\
$\mathbf{5}$ & 41 & 49 & 4 & B \\
$\mathbf{6}$ & 42 & 45 & 3 & B \\
$\mathbf{7}$ & 45 & 45 & 4 & BS \\
$\mathbf{8}$ & 40 & 49 & 9 & BS \\
$\mathbf{9}$ & 48 & 49 & 2 & BS \\
10 & 37 & 50 & 7 & B \\
\hline Rata-Rata Hasil & 41 & 44 & 2 & B \\
Nilai Max & 40.80 & 43 & & \\
Nilai Min & 48 & 46.30 & & \\
\hline
\end{tabular}

Tabel 2. Hasil Pre Test dan Post Test Kelompok Kontrol

\begin{tabular}{ccccc}
\hline \multirow{2}{*}{ No. Sampel } & \multicolumn{2}{c}{ Hasil Tes Kemampuan Passing Bawah } & $\begin{array}{c}\text { Selisih Hasil } \\
\text { Kelompok }\end{array}$ & Klasifikasi \\
\cline { 2 - 4 } $\mathbf{1}$ & \multicolumn{2}{c}{ Kelompok Kontrol } & B-A & \\
$\mathbf{2}$ & 30 & Post Test (B) & 2 & $\mathrm{~S}$ \\
$\mathbf{3}$ & 41 & 32 & 2 & $\mathrm{~B}$ \\
$\mathbf{4}$ & 36 & 43 & 1 & $\mathrm{~S}$ \\
$\mathbf{5}$ & 41 & 37 & 1 & $\mathrm{~B}$ \\
$\mathbf{6}$ & 38 & 42 & 2 & $\mathrm{~B}$ \\
$\mathbf{7}$ & 42 & 40 & 1 & $\mathrm{~B}$ \\
$\mathbf{8}$ & 40 & 43 & 1 & $\mathrm{~B}$ \\
$\mathbf{9}$ & 36 & 41 & 1 & $\mathrm{~S}$ \\
$\mathbf{1 0}$ & 35 & 37 & 3 & $\mathrm{~S}$ \\
Rata-Rata Hasil & 38 & 38 & 2 & $\mathrm{~B}$ \\
Nilai Max & 37.70 & 40 & & \\
Nilai Min & 42 & 39.30 & & \\
\hline
\end{tabular}


Creating Productive and Upcoming Sport Education Profesional Hmzanwadi University

Vol.4, No.2, Desember 2021, Hal. 140-148

e-ISSN 2614-8781

Tabel 3. Klasifikasi Norma Passing Bawah Bola Voli

\begin{tabular}{cc}
\hline Klasifikasi Norma & Perolehan Passing \\
\hline Baik Sekali (BS) & $>47$ \\
Baik (B) & $40-46$ \\
Sedang (S) & $27-39$ \\
Kurang (K) & $17-26$ \\
Kurang Sekali (KS) & $<16$ \\
\hline
\end{tabular}

Tabel 4. Hasil Persentase Berdasarkan Kelompok Penelitian

\begin{tabular}{cccccc}
\hline \multicolumn{2}{c}{ Kelompok Penelitian Eksperimen } & \multicolumn{3}{c}{ Kelompok Penelitian Kontrol } \\
\hline Klasifikasi & Jumlah & Persentase & Klasifikasi & Jumlah & Persentase \\
Baik Sekali & 5 & $50 \%$ & Baik Sekali & 0 & $0 \%$ \\
Baik & 5 & $50 \%$ & Baik & 6 & $60 \%$ \\
Sedang & 0 & $0 \%$ & Sedang & 4 & $40 \%$ \\
Kurang & 0 & $0 \%$ & Kurang & 0 & $0 \%$ \\
Kurang Sekali & 0 & $0 \%$ & Kurang Sekali & 0 & $0 \%$ \\
\hline
\end{tabular}

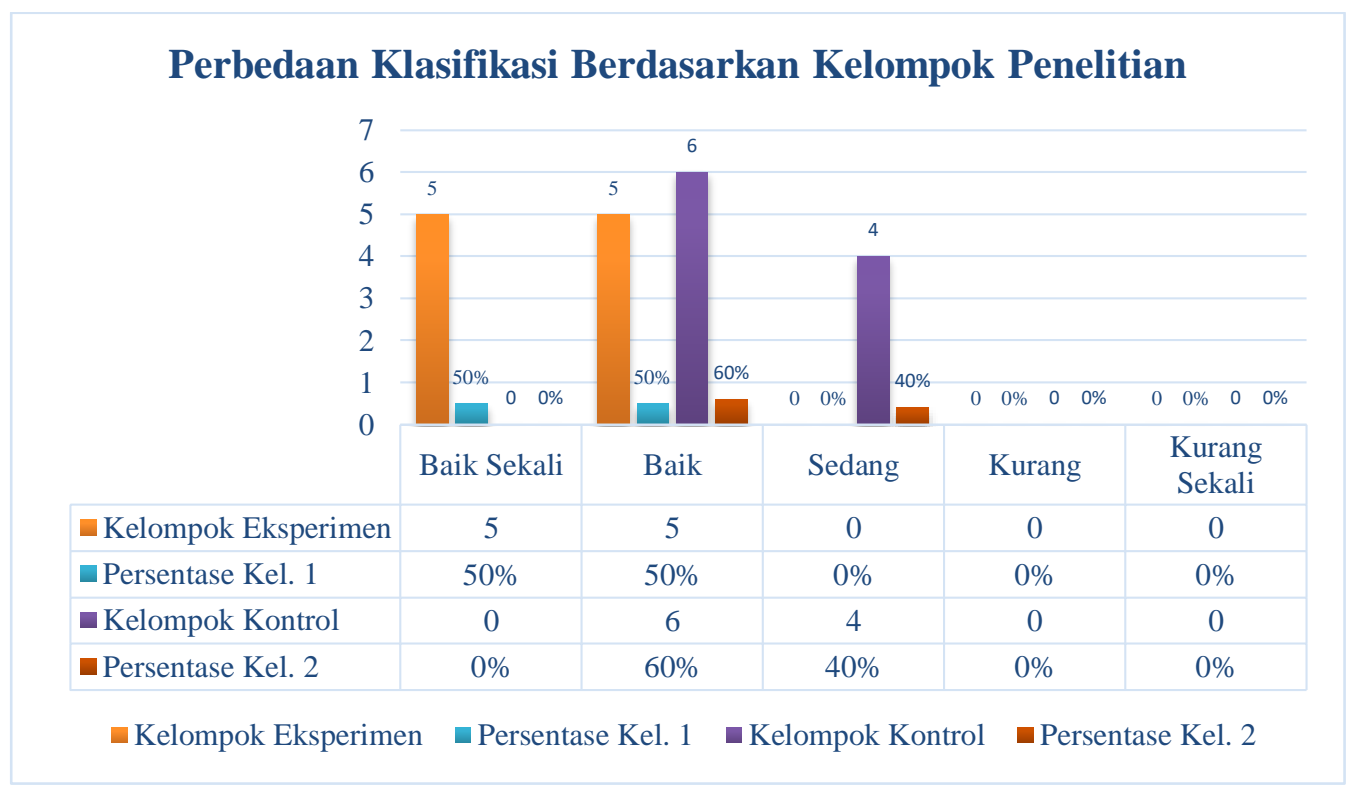

Grapik 1. Perbedaan Klasifikasi Berdasarkan Kelompok Penelitian 
Creating Productive and Upcoming Sport Education Profesional Hmzanwadi University

Vol.4, No.2, Desember 2021, Hal. 140-148

e-ISSN 2614-8781

Tabel 5. Deskripsi Data Pengukuran Variabel pada Kelompok Penelitian

\begin{tabular}{|c|c|c|c|c|c|c|c|c|c|}
\hline \multicolumn{10}{|c|}{ Descriptive Statistics } \\
\hline & \multirow{2}{*}{$\begin{array}{c}\mathrm{N} \\
\text { Statistic }\end{array}$} & \multirow{2}{*}{$\begin{array}{l}\text { Range } \\
\text { Statistic }\end{array}$} & \multirow{2}{*}{$\begin{array}{l}\text { Minimum } \\
\text { Statistic }\end{array}$} & \multirow{2}{*}{$\begin{array}{l}\text { Maximum } \\
\text { Statistic }\end{array}$} & \multirow{2}{*}{$\begin{array}{l}\text { Sum } \\
\text { Statistic }\end{array}$} & \multicolumn{2}{|c|}{ Mean } & \multirow{2}{*}{$\begin{array}{l}\text { Std. Deviation } \\
\text { Statistic }\end{array}$} & \multirow{2}{*}{$\begin{array}{l}\text { Variance } \\
\text { Statistic }\end{array}$} \\
\hline & & & & & & Statistic & Std. Error & & \\
\hline $\begin{array}{l}\text { Pre Test } \\
\text { Eksperimen }\end{array}$ & 10 & 17 & 31 & 48 & 408 & 40.80 & 1.428 & 4.517 & 20.400 \\
\hline $\begin{array}{l}\text { Post Test } \\
\text { Eksperimen }\end{array}$ & 10 & 10 & 40 & 50 & 463 & 46.30 & 1.065 & 3.368 & 11.344 \\
\hline $\begin{array}{l}\text { Pre Test } \\
\text { Kontrol }\end{array}$ & 10 & 12 & 30 & 42 & 377 & 37.70 & 1.146 & 3.622 & 13.122 \\
\hline $\begin{array}{l}\text { Post Test } \\
\text { Kontrol }\end{array}$ & 10 & 11 & 32 & 43 & 393 & 39.30 & 1.075 & 3.401 & 11.567 \\
\hline $\begin{array}{l}\text { Valid N } \\
\text { (listwise) }\end{array}$ & 10 & & & & & & & & \\
\hline
\end{tabular}

Tabel 6. Data Uji Normalitas Shapiro Wilk

\begin{tabular}{l|r|r|r|r|r|r}
\hline \multicolumn{9}{c}{ Tests of Normality } & & \\
\hline & \multicolumn{1}{c}{ Kolmogorov-Smirnov } & \multicolumn{3}{c}{ Shapiro-Wilk } \\
\cline { 2 - 8 } & Statistic & df & \multicolumn{1}{c}{ Sig. } & Statistic & Df & \multicolumn{1}{c}{ Sig. } \\
\hline Pre Test Eksperimen & .230 & 10 & .144 & .911 & 10 & .291 \\
\hline Post Test Eksperimen & .289 & 10 & .018 & .872 & 10 & .105 \\
\hline Pre Test Kontrol & .137 & 10 & $.200^{*}$ & .920 & 10 & .354 \\
\hline Post Test Kontrol & .182 & 10 & $.200^{*}$ & .908 & 10 & .271 \\
\hline
\end{tabular}

*. This is a lower bound of the true significance.

a. Lilliefors Significance Correction

Tabel 7. Data Uji Homogenitas One-Way Anova

\begin{tabular}{l|l|r|r|r|r}
\hline \multicolumn{5}{c}{ Test of Homogeneity of Variances } \\
\hline & $\begin{array}{r}\text { Levene } \\
\text { Statistic }\end{array}$ & df1 & df2 & Sig. \\
\hline Hasil Tes & Based on Mean & .116 & 1 & 18 & .737 \\
\cline { 2 - 7 } Passing & Based on Median & .207 & 1 & 18 & .654 \\
\cline { 2 - 7 } $\begin{array}{l}\text { Bawah } \\
\text { Bola Voli }\end{array}$ & Based on Median and with adjusted df & .207 & 1 & 16.134 & .655 \\
\cline { 2 - 7 } & Based on trimmed mean & .147 & 1 & 18 & .706 \\
\hline
\end{tabular}

Tabel 8. Data Komparasi Antar Kelompok Penelitian Uji Paired t Test

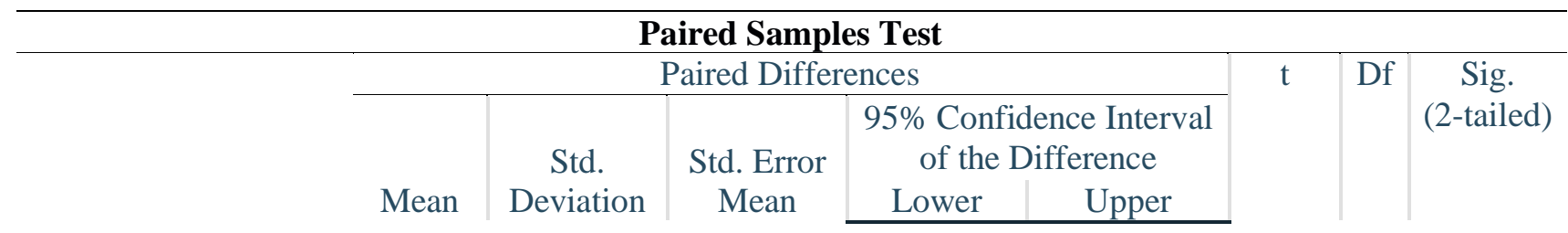




\begin{tabular}{|c|c|c|c|c|c|c|c|c|c|}
\hline $\begin{array}{l}\text { Pair } \\
1\end{array}$ & $\begin{array}{l}\text { Pre Test } \\
\text { Eksperimen - } \\
\text { Post Test } \\
\text { Eksperimen }\end{array}$ & -5.500 & 2.799 & .885 & -7.502 & -3.498 & -7.236 & 9 & .000 \\
\hline $\begin{array}{l}\text { Pair } \\
2\end{array}$ & $\begin{array}{l}\text { Pre Test } \\
\text { Kontrol - Post } \\
\text { Test Kontrol }\end{array}$ & -1.600 & 699 & .221 & -2.100 & -1.100 & -6.214 & 9 & .000 \\
\hline
\end{tabular}

Pembahasan

Berdasarkan analisis data hasil penelitian di atas, kedua kelompok penelitian eksperimen dan kelompok penelitian kontrol sama-sama memberikan dampak perubahan pengaruh terhadap hasil passing bawah bola voli. Secara rata-rata persentase kelompok penelitian eksperimen dengan menggunakan perlakuan treatment berupa pelatihan media dinding dampak pengaruhnya lebih besar dari pada kelompok penelitian kontrol yang hanya menggunakan pelatihan secara konvensional. Pelatihan menggunakan media dinding yang diterapkan pada kelompok eksperimen, yang dijalankan dapat menimbulkan perubahan-perubahan dalam ketepatan passing, atlet juga mudah mengantisipasi bola karena tidak terpancang oleh teman pasangannya dan mudah diarahkan bola pantulannya. Melalui pelatihan fisik tersebut dapat menimbulkan akumulasi nilai dari manfaat pelatihan sehingga akan meningkatkan "dayakarsa" untuk mengikuti pelatihan. Perubahan yang terjadi akibat pelatihan, ditandai dengan meningkatnya fungsi organ tubuh dan otot, yang pada gilirannya akan memberikan efisiensi gerak bagi pelakunya.

Ketepatan passing bola voli dapat dilatih dengan pelatihan menggunakan media dinding dengan sasaran garis lurus. Dengan melakukan pelatihan selama 1 bulan yang frekuensi pelatihan 3 kali dalam 1 minggu sangat berpengaruh terhadap hasil ketepatan passing bola voli. Pelatihan dalam 1 minggu dengan frekuensi 3 kali lebih sedikit kemungkinan menaikan atau peningkatan kapasitas fungsional. Dari hasil penelitian pelatihan menggunakan media dinding dengan sasaran garis lurus dapat memberikan dampak positif bagi atlet jika diterapkan dalam program pelatihan. Hal ini dikuatkan dari beberapa penelitian terkait dengan pengaruh latihan passing menggunakan media dinding dengan sasaran garis lurus, menurut (Fauzi, 2019) dalam penelitiannya menunjukkan dengan menggunakan metode pelatihan dengan menggunakan media dinding memberikan pengaruh yang berarti terhadap ketepatan passing bawah bola voli. Sedangkan menurut (Afdi et al., 2019) dalam penelitiannya juga menunjukkan bahwa terjadi peningkatan secara signifikan kemampuan passing bawah dengan model pelatihan passing. Berdasarkan hasil analisis data uji t berpasangan (paired $t$ test) yang melalui beberapa tahapan, menunjukkan bahwa hasil peningkatan pelatihan pada kelompok eksperimen dengan media dinding, secara persentase lebih tinggi pengaruhnya jika diterapkan, dari pada pelatihan pada kelompok kontrol yang hanya menggunakan pelatihan secara konvensional. Hal ini sebagai rekomendasi bagi pelatih maupun atlet dengan media pelatihan tersebut bila diterapkan secara teratur, terprogram, berkesinambungan, serta disiplin yang tinggi terbukti berkontribusi dapat meningkalkan keterapan passing bawah bola voli, sehingga pelatihan tersebut dapat diterapkan.

\section{Simpulan}

Berdasarkan tahapan-tahapan penelitian, pengumpulan data, serta menguji hasil tes ketepatan passing bawah bola voli secara statistik bahwa, pelatihan kelompok eksperimen 
dengan pelatihan kelompok kontrol sama-sama berdampak positif bagi atlet, karena hasilnya menunjukkan pengaruh yang signifikan. Tetapi pelatihan kelompok eksperimen yang menggunakan perlakuan/treatment berupa media dinding dengan sasaran garis lurus dampak pengaruhnya lebih baik atau lebih tinggi bagi atlet, dari pada pelatihan kolompok kontrol yang tidak menggunakan perlakuan/treatment dengan secara konvensional. Dalam hal ini, maka dapat diambil kesimpulan bahwa pelatihan menggunakan media dinding dengan sasaran garis lurus berpengaruh terhadap ketepatan passing bawah Atlet Klub Bola Voli Puput Kecamatan Prambon Sidoarjo.

\section{Daftar Pustaka}

Afdi, R. B., Zulman, Z., \& Asmi, A. (2019). Pengaruh Model Latihan Passing Terhadap Kemampuan Passing Bawah Dan Passing Atas Pemain Bolavoli.SportScience,19(1),3340.https://doi.org/10.24036/jss.v19i1.6

Arikunto, Suharsimi. 2006. Prosedur Penelitian Suatu Pendekatan Praktik. Jakarta: Rineka Cipta.

Ahmadi, Nuril. 2007. Panduan Olahraga Bola Voli. Surakarta: Era Pustaka Utama.

Alwijaya, m. e. (2018). penerapan metode drill untuk meningkatkan hasil belajar passing bawah bola voli siswa kelas vii. a smp negeri 2 batukliang tahun. Jurnal Ilmiah Mandala Education, 4(2), 172-184.

Bompa, T.O. 1994. Periodization Training for Sport. Diterjemahkan oleh Sarwono.1991. Surabaya: Fakultas Pasca Sarjana Universitas Airlangga Surabaya.

Depdiknas. (1999). Petunjuk Tes Keterampilan Bola Voli Usia 13-15 tahun. Jakarta: Pusat Kesegaran Jasmani dan Rekreasi.

Fauzi. (2019). Pengaruh Metode Latihan Dinding dan Metode Latihan Berpasangan Terhadap Ketepatan Passing. Muara Olahraga, 2, 218-227.http://ejournal.stkipmmb.ac.id/index.php/pjkr/article/view/242/149

Hidayat, M. T. (2015). Peningkatan Kemampuan Pass Bawah dalam Permainan Bola Voli Melalui Latihan Pass Bawah Duduk Berdiri Pada Bangku dan Pass Bawah dengan Berjalan pada Siswa Kelas VI SDN Tanggul Wetan 01 Jember. Jurnal Pancaran, 4(1), 153-164

Hadi, Sutrisno. 1993. Metodologi Research. Yogyakarta: UGM.

Hambali, S. (2016). Pembelajaran Passing Bawah Menggunakan Metode Bermain Pada Permainan Bola Voli. Jurnal Pendidikan Olahraga, 5(1), 58-70.

Juniaturrahman, M. (2016). Pengaruh Latihan Wall Volley Terhadap Keakurasian Passing Bawah Pada Olahraga Bola Voli (Studi Pada Peserta Ekstrakurikuler Sma Pgri Sumenep). Jurnal Kesehatan Olahraga, 4(4).

Kardiyanto, D. W., \& Or, S. (2020). Kepelatihan Bola Voli. Zifatama Jawara.

Mardian, R. (2020). Pengaruh Latihan Mengumpan Ke Dinding Dan Berpasangan Terhadap Keterampilan Passing Bawah Bola Voli: Effect of wall and pair pass practice on volleyball bottom pass skills. Cerdas Sifa Pendidikan, 9(1), 1-11.

M. Yunus. 1992. Olahraga Pilihan Bola Voli. Jakarta: Depdikbud.

Nurhasan. 1998. Modul Tes dan Pengukuran Keolahragaan. Bandung: UPI

Nursalam, 2016, metode penelitian, \& Fallis, A. . (2013). Journal of Chemical Information and Modeling, 53(9), 1689-1699. 
Creating Productive and Upcoming Sport Education Profesional Hmzanwadi University Vol.4, No.2, Desember 2021, Hal. 140-148

e-ISSN 2614-8781

Olahraga, P. K., Keolahragaan, F. I., \& Semarang, U. N. (2015). Pengaruh Latihan Passing Bawah Dengan Ketepatan Passing Bawah Dalam Universitas Negeri Semarang.

Priyono, I. H. (2020). Pengaruh Latihan Wallbounce Untuk Meningkatkan Kemampuan Passing Bawah Bola Voli Siswa Kelas XI IPS 3 SMA N 1 Jatiroto. 1(1).

Putri, O. V. (2019). Pengaruh Bentuk Latihan Passing Bawah Perorangan dan Passing Bawah Berpasangan Terhadap Kemampuan Passing Bawah Bolavoli.

Rasyono, R. (2019). pengaruh latihan bola pantul terhadap keterampilan passing bawah bola voli pada ekstrakurikuler smp negeri 30 muaro jambi. Riyadhoh: Jurnal Pendidikan Olahraga, 2(1), 22-26.

Rahmat, D., \& Wahidi, R. (2018). Pengaruh Pembelajaran Passing Berpasangan Terhadap Keterampilan Passing Bawah Dalam Permainan Bola Voli. JUARA :JurnalOlahraga,3(2),96.https://doi.org/10.33222/juara.v3i2.241

Sugiyono. 2007. Metode Penelitian Kuantitatif Kualitatif dan R\&D. Bandung:Alfabeta

Saputra, D. I. M., \& Gusniar, G. (2019). Meningkatkan Hasil Belajar Passing Bawah Bola Voli melalui Bermain Melempar Bola. Gelanggang Olahraga: Jurnal Pendidikan Jasmani Dan Olahraga (JPJO), 3(1), 64-73. https://doi.org/10.31539/jpjo.v3i1.862

Sutiswo, S., \& Hambali, S. (2018). implementasi metode bermain dalam pembelajaran passing bawah bola voli di sekolah dasar. Jurnal Kependidikan Jasmani dan Olahraga, 2(2), 2630.

Sujito, S. (2020). pengembangan model pembelajaran passing bawah bolavoli jurnal penjakora, 7(1), 30-39.

Sukma Aji. (2016). Peraturan Permainan Bolavoli. Jakarta.

Teguh Susanto. (2016). Buku Pintar Olaharaga. Yogyakarta: (KDT) Susanto, Teguh

Toyoda, H. (2012). Volleyball for Beginners: Mini and Mass Volleyball. FIVB Level 1 Coaches Manual, 1, 29-68.

Tomi, A. (2017). Pengaruh Latihan Passing Dipantulkan Ke Passing Dalam Pembelajaran Bolavoli Pada Kelas X1 Dan X2 Sma Negeri 1 Sampung. 1.

Tawakal, I. (2020). Buku Jago Bola Voli. Ilmu Cemerlang Group.

Wijaya, M. R. A., \& Pd, M. (2019). Jurnal utile pengaruh latihan passing bawah menggunakan media dinding dan berpasangan terhadap peningkatanteknik passing bawah bolavoli pada ekstrakurikuler smp al-irsyad. $V$ (November), 160-164.

Yakhsya, M. (2019). Pengaruh Permainan Bola Pantul Terhadap Peningkatan Kemampuan Passing Bawah Bola Voli (Pre Eksperimen Siswa Ekstrakurikuler di SD Negeri Gudang Kecamatan Tigaraksa Kabupaten Tangerang) (Doctoral dissertation, UIN SMH BANTEN).

Zmiyati, U., \& Poernomo, N. S. (2019). JUPE: Jurnal Pendidikan Mandala. JUPE: Jurnal Pendidikan Mandala, 4(5), 276-280. 